\title{
Prevalence of diabetes and its relation with age and sex in Turaif city, northern Saudi Arabia in 2016-2017
}

Nour Homoud Alanazi ${ }^{2}$, Mahmoud Mohammed Alsharif ${ }^{1}$, Ghazala Rasool ${ }^{3}$, Ahmed Bin Hashash Alruwaili², Asem Matrouk Zayed Alrowaili ${ }^{2}$, Ahmed Saud Aldaghmi ${ }^{2}$, Mohammad Khalil Dughaieum Al Shkra ${ }^{2}$, Fatimah Awadh Alrasheedi ${ }^{2}$, Ghadah Saleem Alenezi ${ }^{2}$, Mona Theyab Alanazi ${ }^{2}$

${ }^{1}$ Intern, Faculty of Medicine, Northern Border University, Arar, Saudi Arabia

${ }^{2}$ Student, Faculty of Medicine, Northern Border University, Arar, Saudi Arabia

${ }^{3}$ Assistant Professor, Department of Internal Medicine, Northern Border University, Arar, Saudi Arabia

\section{Type of article: Original}

\begin{abstract}
Background: The prevalence of diabetes in Saudi Arabia has increased dramatically during the last decades. This increase has been attributed to significant changes in cultural and socio-economic factors.

Objective: The aim of this study was to determine prevalence of diabetes and its relation with age and sex in Turaif city, northern Saudi Arabia.

Methods: This was a cross-sectional study carried out during the academic year 2016-2017 over a period of 6 months (October 01, 2016 to March 30, 2017). A total of 1,287 Saudi national individuals of both sexes, aged from 1 year to more than 65 years were included in the study. Data were collected by a predesigned questionnaire covering medical history of diabetes, age and sex.

Results: Mean age $( \pm$ SD) was $24.29( \pm 13.96)$ years with the minimum age at 1 year and the maximum age at 93 years, male to female ratio was $42.5 \%$ to $57.5 \%$. The total prevalence of DM among the studied population was $5.8 \%$ and pre-diabetic cases were $6.8 \%$. There were significant relationships between age/sex, and the occurrence of diabetes among the studied population $(\mathrm{p}<0.05)$.

Conclusions: The total prevalence rate of DM among the studied population of Turaif city, northern Saudi Arabia was $5.8 \%$ and pre-diabetic cases were $6.8 \%$. Awareness campaigns and prevention programs about diabetes should be instituted and the existing ones must be strengthened. Adequate commitment from the Ministry of Health is also advocated.

Keywords: Diabetes mellitus; Total prevalence; Different age groups; Turaif, Saudi Arabia; Random blood sugar
\end{abstract}

\section{Introduction}

Diabetes mellitus (DM) is a major public health problem worldwide. It is a group of metabolic diseases in which there are high blood sugar levels over a prolonged period (1). Diabetes is due to either the pancreas not producing enough insulin or the cells of the body not responding properly to the insulin produced (2). There are three main types of diabetes mellitus; Type $1 \mathrm{DM}$, known as juvenile diabetes, results from the pancreas's failure to produce enough insulin, type $2 \mathrm{DM}$ begins with insulin resistance, a condition in which cells fail to respond to insulin properly and gestational diabetes is the third main form, and occurs when pregnant women without a previous history of diabetes develop high blood sugar levels (3). Following an extensive international study gathering and analyzing worldwide data on diabetes, results revealed that the number of adults with diabetes reached 347 million in 2008, which is double that of the amount reached 1980 (4). In 1987, diabetes prevalence was at 4.3\%, but by 2004 it had increased to $23.7 \%$ (5). Analysis of data from 91 countries to calculate age- and sex-specific diabetes prevalence was carried out and applied to national population estimates to determine prevalence of diabetes for all 216 countries between 2010 and 2030. The world prevalence of diabetes among adults (aged 20-79 years) was estimated as $6.4 \%$, affecting 285 million adults by 2010 and this figure will increase to $7.7 \%$ and 439 million adults by the year 2030. It is estimated that between 2010 and 2030, the number of adults with diabetes in developing

\section{Corresponding author:}

Nour Homoud Alanazi, Faculty of Medicine, Northern Border University, Arar, Saudi Arabia.

Tel: +966.542407590, Email: nor_h95@hotmail.com

Received: July 11, 2017, Accepted: August 12, 2017, Published: September 2017

iThenticate screening: August 12, 2017, English editing: September 02, 2017, Quality control: September 14, 2017

(C) 2017 The Authors. This is an open access article under the terms of the Creative Commons Attribution-NonCommercialNoDerivs License, which permits use and distribution in any medium, provided the original work is properly cited, the use is non-commercial and no modifications or adaptations are made. 
countries will see an increase of $69 \%$ and there will be an increase of $20 \%$ in developed countries (6). A study on diabetes in Saudi Arabia (7) revealed that a total of 4,004 subjects (23.7\%), out of 16,917 were diagnosed as having DM. Thus, in Saudi Arabia, the total prevalence of DM obtained from this study is $23.7 \%$. The prevalence in males and females were $26.2 \%$ and $21.5 \%$ respectively $(\mathrm{p}<0.00001)$. The estimated age-adjusted prevalence for the Saudi population for the year 2000 is $21.9 \%$. Diabetes mellitus was shown to be more prevalent among Saudis living in urban areas which was $25.5 \%$, compared to Saudis living in rural areas which was $19.5 \%(\mathrm{p}<0.00001)$. Another study conducted in Arar, Saudi Arabia, showed that the prevalence of diabetes mellitus among adult educated and employed males of Arar city was $14.8 \%$. There is a high statistically significant difference between different age groups of the participants as regards diabetes $(p<0.001)$, but here is no statistically significant difference between obese and non-obese ( $>0.05)$. There is also a highly significant relation between the family history of diabetes and diabetes $(\mathrm{p}<0.001)$. Diabetes was found in $17.8 \%$ and $9.8 \%$ of physically inactive and physically active participants respectively, and there is statistically significant relation between diabetes and physical activity $(\mathrm{p}<0.05)(8)$. The aim of this study is to measure prevalence of diabetes and its relation with age and sex in the studied population of Turaif city, northern Saudi Arabia.

\section{Material and Methods}

This cross-sectional study was carried out among both sexes of a Turaif population in northern Saudi Arabia. The study was carried during the academic year 2016-2017 over a period of 6 months (October 01, 2016 to March 30, 2017). The formula sample size was estimated based on the formula $n=z^{2} p(1-p) / e^{2}$, considering the prevalence of stunted growth in Turaif is 50\%, target population more than 10,000, and study power $95 \%$, absolute error $5 \%$, and a nonresponse rate $20 \%$. A total of 1,287 individuals of both sexes who are Saudi nationals aged from 1 year to more than 65 years were included in the study. Data were collected by means of personal interview with the sampled population using a predesigned questionnaire covering the following items: 1) Socio-demographic characteristics including age and sex; 2) Blood sample drawn under complete septic conditions to determine random blood glucose level. A person was considered diabetic if random blood sugar was $\geq 200 \mathrm{ml} / \mathrm{dl}$. Collected data were coded and analyzed by SPSS version 15 (SPSS Inc., Chicago, Illinois, USA). The Chi-square test was used as a test of significance, and differences were considered significant at $P$ value 0.05 or less. Permission to conduct the study was obtained from the Research and Ethics Committee of the Northern Border University, Kingdom of Saudi Arabia. The questionnaire had a brief introduction to the students by explaining the aims and benefits of the study. Anonymity and confidentiality of data were maintained throughout the study. There was no conflict of interest.

\section{Results}

Mean age $( \pm$ SD) was $24.29( \pm 13.96)$ years with the minimum age at 1 year and the maximum age at 93 years, male to female ratio was $42.5 \%$ to $57.5 \%$. About $58.7 \%$ of the diagnosed cases were aged between $36-65$ years old while $30.7 \%$ were aged between 17-35 years old. The highest percentage of pre-diabetics was at the 36-65 years old (42.5\%). Table 1 illustrates the socio-demographic characteristics of studied cases, in Turaif city, northern Saudi Arabia, 2016-2017. Table 2 illustrates prevalence of DM in Turaif city among studied cases in Turaif city, northern Saudi Arabia in 2017.

Table 1. Socio-demographic characteristics of studied cases, in Turaif city, northern Saudi Arabia, 2016-2017

\begin{tabular}{|l|l|l|l|}
\hline Parameter & \multicolumn{2}{|c|}{ Frequency $(\mathrm{n}=1287)$} & Percent $(\%)$ \\
\hline Age (year); 24.29 $( \pm 13.964)$ & $0-16$ & 428 & 33.3 \\
\cline { 2 - 4 } & $17-35$ & 605 & 47.0 \\
\cline { 2 - 4 } & $36-65$ & 247 & 19.2 \\
\cline { 2 - 4 } & More then 65 & 7 & 0.5 \\
\hline \multirow{2}{*}{ Sex } & Male & 547 & 42.5 \\
\cline { 2 - 4 } & Female & 740 & 57.5 \\
\hline
\end{tabular}

Table 2. Prevalence of DM among studied cases in Turaif city, northern Saudi Arabia, 2016-2017

\begin{tabular}{|l|l|l|}
\hline Diagnosis & Frequency $(\mathrm{n}=1287)$ & $\%$ \\
\hline Normal & 1125 & 87.4 \\
\hline Pre-diabetic & 87 & 6.8 \\
\hline Diabetic & 75 & 5.8 \\
\hline Total & 1287 & 100.0 \\
\hline
\end{tabular}


The total prevalence of DM among studied cases was $5.8 \%$, pre-diabetic cases were $6.8 \%$ and normal cases were $87.4 \%$. According to our findings, 75 people (5.8\%) were diabetic cases, 87 people $(6.8 \%)$ were pre-diabetic cases and 1,125 people $(87.4 \%)$ were normal cases. Table 3 , illustrates the relationship between diabetic patients and age among studied cases in Turaif city, northern Saudi Arabia in 2017. There is significant effect of age ( $<<0.05$ ). Finally, Table 3 illustrates the relationship between diabetic patients and sex among studied cases in Turaif city, northern Saudi Arabia in 2017. There is significant effect of sex $(\mathrm{p}<0.05)$.

Table 3. Relationship between diabetes and age among studied cases in Turaif city, northern Saudi Arabia, 20162017

\begin{tabular}{|c|c|c|c|c|c|c|c|}
\hline \multirow{2}{*}{\multicolumn{2}{|c|}{ Variable }} & \multicolumn{3}{|l|}{ Diagnosis } & \multirow{2}{*}{$\begin{array}{l}\text { Total } \\
(\mathrm{n}=1287)\end{array}$} & \multirow[t]{2}{*}{ Chi-Square } & \multirow[t]{2}{*}{ p-value } \\
\hline & & Normal $(n=1125)$ & Pre-diabeti $(n=87)$ & Diabetic $(n=75)$ & & & \\
\hline \multirow{8}{*}{$\begin{array}{l}\text { Age } \\
\text { (year) }\end{array}$} & \multirow[t]{2}{*}{$0-16$} & 399 & 24 & 5 & 428 & \multirow[t]{8}{*}{1.461} & \multirow[t]{8}{*}{0.00} \\
\hline & & $35.5 \%$ & $27.6 \%$ & $6.7 \%$ & $33.3 \%$ & & \\
\hline & \multirow[t]{2}{*}{$17-35$} & 557 & 25 & 23 & 605 & & \\
\hline & & $49.5 \%$ & $28.7 \%$ & $30.7 \%$ & $47.0 \%$ & & \\
\hline & \multirow[t]{2}{*}{$36-65$} & 166 & 37 & 44 & 247 & & \\
\hline & & $14.8 \%$ & $42.5 \%$ & $58.7 \%$ & $19.2 \%$ & & \\
\hline & \multirow[t]{2}{*}{$>65$} & 3 & 1 & 3 & 7 & & \\
\hline & & $0.3 \%$ & $1.1 \%$ & $4.0 \%$ & $0.5 \%$ & & \\
\hline \multirow[t]{4}{*}{ Sex } & \multirow[t]{2}{*}{ Male } & 494 & 33 & 20 & 547 & \multirow[t]{4}{*}{9.354} & \multirow[t]{4}{*}{0.009} \\
\hline & & $43.9 \%$ & $37.9 \%$ & $26.7 \%$ & $42.5 \%$ & & \\
\hline & \multirow[t]{2}{*}{ Female } & 631 & 54 & 55 & 740 & & \\
\hline & & $56.1 \%$ & $62.1 \%$ & $73.3 \%$ & $57.5 \%$ & & \\
\hline
\end{tabular}

\section{Discussion}

Diabetes is a multifactorial disease of considerable heterogeneity (9). The prevalence of diabetes worldwide will see an increase of $42 \%$ between the years 2003 and 2025 (10). Prevalence data are important to show the effectiveness of the current health care programs. This study is a cross-sectional study, carried out in Turaif city, Saudi Arabia over a period of 6 months (October 01, 2016 to March 30, 2017). The main objective of the study was to determine the prevalence of diabetes and it's relation with age and sex. Overall, 47.0\% aged between 17-35 years old with mean age $( \pm \mathrm{SD})$ of $24.29( \pm 13.96)$. The present study revealed that the overall prevalence of diabetes was $5.8 \%$. Our finding is less than the reported prevalence data from the Gulf region in Bahrain (25.7\%) and Oman (16.1\%) (11, 12). A 2010 study estimated that more than 92 million Chinese adults have the disease, with another 150 million showing early symptoms (13). In India, diabetes currently affects more than 62 million Indians, which is more than $7.1 \%$ of the adult population (14). Another study in Canada found that almost 2.4 million Canadians (6.8\%) have been diagnosed with type 1 or type 2 diabetes, based on 2009 chronic disease surveillance data (15). Age is known to be an important determinant of diabetes since blood glucose concentrations tend to rise with age (16). In our study, there was high significant relation between age and number of diagnosed diabetic cases. A study conducted in Saudi Arabia (17) showed that the mean ( \pm SD) age for onset of diabetes in males and females was 57.5 (13.1) and 53.4 (13.1) years, respectively $(\mathrm{p}<0.0001)$. Females $<50$ years old had a higher prevalence than males in the corresponding age range, $34.1 \%$ and $25.1 \%$, respectively $(0<0.0001)$. The prevalence of diabetes decreased in patients older than 70 years. Another study among an urban Iranian population (18) showed that the prevalence of DM increased with advancing age from $4 \%$ in subjects from 30 to 39 to $22.9 \%$ in subjects $\geq 60$ ( $p<0.001$ ). Also, the prevalence of pre-diabetics increased from $3.1 \%$ in subjects 30 to 39 to $20.9 \%$ in the $\geq 60$ age groups (p<0.001), but there was no statistical difference between age groups and prevalence of NDM. Another study in Riyadh, Saudi Arabia, revealed that the mean age of 99 type 2 diabetic patients was 57 years (19). Regarding sex, this study found that females had a higher percentage of diabetic patients than males $(73.3 \%, 26.7 \%$ respectively). Those results did not agree with the Canadian study (16) which found a higher proportion of males than females $(\neg 54 \%$ males, $46 \%$ females) with diabetes, studies in the United States found a higher proportion of females $\neg(42 \%$ males Vs. $58 \%$ females) with diabetes (20). While Al-Nozha et al. (7) found that the prevalence in males and females were $26.2 \%$ and $21.5 \%(p<0.00001)$. In the Iranian study, the results showed that prevalence of diabetes mellitus was $11.6 \%$; $11.1 \%$ in men and $12.1 \%$ in women with no significant difference between them. In another Saudi study (17) the prevalence of diabetes was $34.1 \%$ in males and $27.6 \%$ in females $(p<0.0001)$.

\section{Conclusions}

The total prevalence rate of DM among the studied population of Turaif city, northern Saudi Arabia was 5.8\% and pre-diabetic cases were $6.8 \%$, females had the higher percentage of diabetic patients than males. Awareness 
campaigns should be held more often in different neighborhoods of the city, prevention programs about diabetes should be instituted and the existing ones must be strengthened. Health education settings should be more specific and clear for the public. Adequate commitment from the Ministry of Health is also advocated.

\section{Acknowledgments:}

The authors are very grateful to Northern Border University for their continuous support and guidance. We also would like to extend our appreciation to, Reem Sebeh Alhazmi, Abdulmajeed Ahmed Alenazi and Naif Gharbi Alenezi for helping us in collection of data.

\section{Conflict of Interest:}

There is no conflict of interest to be declared.

\section{Authors' contributions:}

All authors contributed to this project and article equally. All authors read and approved the final manuscript.

\section{References:}

1) World Health Organization "About diabetes". Archived from the original on 31 March 2014; Retrieved 4 April 2014.

2) Gardner, Dolores. Shoback, edited by David G "Chapter 17". Greenspan's basic \& clinical endocrinology (9th ed.). McGraw-Hill Medical. 2011;

3) WHO. "Diabetes Fact sheet $N^{\circ} 312 "$ 2013. Archived from the original on 26 August 2013. Retrieved 25 March 2014.

4) Al-Hazzaa HM. Prevalence of physical inactivity in. Saudi Arabia: A brief review. East Mediterr Health J. 2004;(10): 663-70.

5) Amin TT, Al-Sultan AI, Ali A. Overweight and obesity and their relation to dietary habits and sociodemographic characteristics among male primary school children in Al-Hassa, Kingdom of Saudi Arabia. Eur JNutr. 2008;(47): 310-18. DOI: 10.1007/s00394-008-0727-6

6) J.E. Shaw, R.A. Sicree, P.Z. Zimmet. Global estimates of the prevalence of diabetes for 2010 and 2030. Diabetes Research and Clinical Practice. 2010;87:(1), 2010;4-14. Doi: 10.1016/j.diabres.2009.10.00

7) Al-Nozha MM, Al-Maatouq MA, Al-Mazrou YY, Al-Harthi SS, Arafah MR, Khalil MZ. Saudi Med J. 2004 Nov;25(11):1603-10.

8) Nagah Mohamed AF,Ahmed Naser Esh,Mohanna JA, Khaled AA, Abdullah MA,Thamer OA, et al. DIABETES MELLITUSAMONG ADULT MALE POPULATION OF ARAR CITY, NORTHERN SAUDI ARABIA. International journal of advanced research. Int. J. Adv. Res. 2017;5(1), 1215-20.

9) Zimmet P, Alberti KG, Shaw J. Global and societal-implications of the diabetes epidemic. Nature. 2001;(414):782-7. DOI: $10.1038 / 414782 \mathrm{a}$

10) International Diabetes Federation: Diabetes Atlas 2003. Brussels: International Diabetes Federation; 2003.

11) Hamadeh RR. Noncommunicable diseases among the Bahraini population: A review. East Mediterr Health J. 2000;(6)1091-7.

12) Al-Lawati JA, Al Riyami AM, Mohammed AJ, Jousilahti P. Increasing prevalence of diabetes mellitus in Oman. Diabet Med. 2002;(19)954-7. DOI: 10.1046/j.1464-5491.2002.00818.x

13) "China faces 'diabetes epidemic', research suggests". March 25, 2010.

14) IANS. "Diabetes can be controlled in 80 percent of Cases in India". Available from: news.biharprabha.com.

15) Public Health Agency of Canada, Diabetes in Canada: Facts and figures from a public health perspective. Ottawa, 2011.

16) West KM. Epidemiology of diabetes and its vascularlesions. Elsevier Biomedical Press, New York, 1978.

17) Khalid AA,Khalid SA,Samia AB. Prevalence of diabetes mellitus in a Saudi community. Ann Saudi Med. 2011;31(1): 19-23. DOI: 10.4103/0256-4947.75773

18) Karamatollah R,Mohammad Sh, Abdolreza SJ. Relation of type 2 diabetes mellitus with gender, education, and marital status in an Iranian urban population. Rep Biochem Mol Biol. 2013;1(2): 64-8.

19) Assim A,Khalid ABA. Assessment of care for type 2 diabetic patients at the primary care clinics of a referral hospital. Saudi Med J. 2004 Nov;25(11):1603-10.

20) Harris MI (1995) Diabetes in America. In: National Diabetes Data Group. 2nd edn. NIH Publication No. $95 \pm 1468$, B. C.K.Choi et al. Risk factors for diabetes mellitus by age and sex. 1229 National Institutes of Health, National Institute of Diabetes and Digestive and Kidney Diseases, Bethesda,1995; 1-13.

21) Somannavar S, Ganesan A, Deepa M, Datta M, Mohan V. Random Capillary Blood Glucose Cut Points for Diabetes and Pre-Diabetes. Derived From Community-Based Opportunistic Screening in India.Diabetes Care. 2009 Apr; 32(4): 641-3. DOI: 10.2337/dc08-0403 